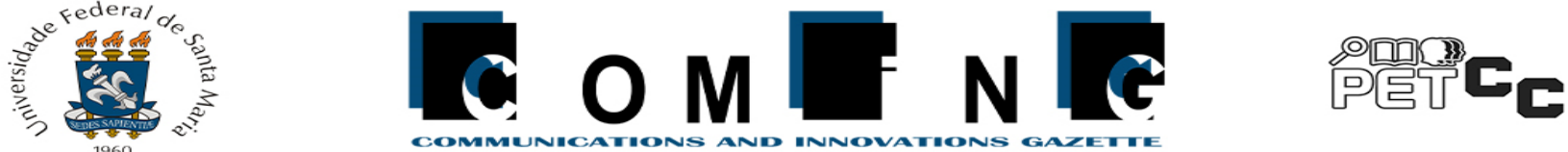

\section{Curso de Geogebra para Capacitação de Professores da Rede Pública de Ensino}

\author{
Francielle V. Pereira ${ }^{1}$, Giovani R. Librelotto ${ }^{1}$ \\ ${ }^{1}$ Centro de Tecnologia - Universidade Federal de Santa Maria (UFSM) \\ 97105-900 - Santa Maria - RS - Brasil \\ \{fvpereira, librelotto\}@inf.ufsm.br
}

\begin{abstract}
Due to social distance, a measure taken to prevent the Covid-19 pandemic from advancing, public and private schools went through a period of adaptation to maintain education through a hybrid system or just remote classes. With this in mind, the Geogebra course for teachers was created, with the aim of instructing and encouraging teachers of mathematics to make their classes more interactive and attractive to their students with the use of Geogebra. The first class was created in late September and had 76 students. Among all, 27 students managed to complete the course successfully, guaranteeing a certification.
\end{abstract}

Resumo. Devido o distanciamento social, medida tomada para evitar o avanço da pandemia do Covid-19, escolas públicas e privadas sofreram um período de adaptação para manter o ensino através de um sistema híbrido ou apenas remoto. Pensando nisso, criou-se o curso de Geogebra para professores, com o objetivo de instruir e incentivar docentes da matemática à tornarem suas aulas mais interativas e atrativas para seus estudantes com a utilização do Geogebra. A primeira turma foi criada no final de setembro e contou com 76 alunos. Dentre todos, 27 alunos conseguiram concluir o curso com êxito, garantindo a certificação.

\section{Introdução}

A pandemia trouxe consigo diversos problemas e desafios para todos os setores. Na educação brasileira, o impacto causado em todos os níveis da educação foi notável, pois grande parte das instituições de ensino não estavam preparadas para desenvolver atividades remotamente. O despreparo e a dificuldade com tecnologias são obstáculos enfrentados tanto por docentes quanto discentes.

Com o intuito de auxiliar a comunidade durante esse período difícil de distanciamento social, o PET-CC (Programa de Ensino Tutorial de Ciência da Computação) iniciou uma série de cursos online para facilitar a utilização de tecnologias disponíveis. Como a matemática é uma disciplina que a maioria dos estudantes possui dificuldade, mesmo presencialmente [Masola and Allevato 2019], o PET-CC criou o curso introdutório ao Geogebra.

Segundo o site oficial da ferramenta ${ }^{1}$, o Geogebra é um software gratuito de matemática dinâmica para todas as modalidades de ensino. É um dos líderes de softwares

\footnotetext{
${ }^{1}$ https://www.geogebra.org/about
} 
matemáticos, reunindo diferentes áreas, como Geometria, Álgebra, Planilha de Cálculo, Gráficos, Probabilidade, Estatística e Cálculos Simbólicos em uma única aplicação.

Com o auxílio do Geogebra, os professores são capazes de tornar tanto as atividades avaliativas quanto as explicativas mais atrativas e lúdicas, podendo utilizar o método contrucionista de Seymour Papert [Halberstadt 2016]. A iniciativa do curso foi idealizada devido a realidade pandêmica que a sociedade enfrenta atualmente, porém os conhecimentos obtidos no curso podem ser utilizados para aplicações da ferramenta em aulas presenciais, seja para tarefas ou demonstrações.

O presente trabalho está organizado da forma que segue: na Seção 2] são revisados alguns trabalhos que possuem relação com este bem como a fundamentação teórica envolvida; na Seção 3 propõe-se a explanar como os materiais foram produzidos e organizados e qual a didática utilizada; a Seção 4 relata as aprovações e feedbacks obtidos e a Seção 5 traz os apontamentos finais e segmentos futuros.

\section{Referencial Teórico}

A utilização do Geogebra para o ensino da geometria [Brandt and Montorfano 2008] destaca o papel do professor em possuir capacidade de conduzir os estudos, contextualizando-os para os alunos, pois o computador por si só pode não conduzir a aprendizagem de matemática [Halberstadt 2016].

A maioria dos trabalhos relacionados ao uso da ferramenta no ensino possuem foco na geometria, pois facilita o entendimento permitindo que os estudantes interajam com os objetos e sólidos geométricos. Porém, por ser um software de matemática dinâmica, o Geogebra pode ser utilizado para outros conteúdos, como o uso em probabilidade e estatística [Bortolossi 2016].

Em um dos principais referenciais ao qual o presente trabalho baseou-se para a estruturação do curso, é apresentado como foi elaborado e criado o curso de Google Classroom, que assim como este, também foi ofertado pelo PET-CC e voltado para professores da rede pública de ensino [Fantinel and et al. 2020]. Devido à alta demanda do curso, percebeu-se a importância e a necessidade de contribuir e auxiliar a comunidade para que possam lidar com as diferentes tecnologias ofertadas.

Para validar a ideia, alguns artigos foram utilizados, como [Brandt and Montorfano 2008] e [Halberstadt 2016], visando verificar a eficiência da aplicação do Geogebra no ensino de diferentes área das ciências exatas. Recorrer à novas alternativas desde as séries iniciais é de suma importância para a formação dos alunos, pois prepara-os para a sociedade na era tecnológica além de servir como motivação e auxílio no aprendizado da matemática [Freire et al. 2013].

Existe uma série de motivos para a escolha referente a utilização do Geogebra como ferramenta de ensino da matemática. Para [Preiner 2008], o software é open-source e gratuito, podendo ser baixado em computadores sem restrição de sistemas operacionais. Além disso, o Geogebra é muito parecido com o Cabri Geometry? um software de geometria dinâmica, o que leva a acreditar que o Geogebra pode ter a mesma eficiência quando utilizado para o ensino.

\footnotetext{
${ }^{2}$ https://www.cabri.com/
} 
O software conta com muitas funcionalides e opções diferentes, mas uma que pode ser comum a todas as janelas do Geogebra é a animação de objetos presentes na tela. Ressalta-se o uso de animações para realização de demonstrações matemáticas e resolução de problemas. A inserção de animações em applets do Geogebra faz com que a explanação do conteúdo em questão torne-se mais atrativo e visual, facilitando o entedimento de diversos temas, como por exemplo, geometria espacial [Mathias et al. 2019].

\section{Metodologia}

Para organização do curso algumas etapas foram seguidas. Primeiramente, escolheu-se o público alvo, no qual definiu-se que o foco seria professores de escolas públicas estaduais da área de matemática. Essa escolha deve-se principalmente pela grande dificuldade que escolas estaduais estão tendo neste momento de pandemia para tornar suas aulas atrativas ao público infantojuvenil.

Realizou-se, então, a estruturação do curso, como a elaboração da ementa, a realização de vídeoaulas e o desenvolvimento de atividades avaliativas, baseando-se em cursos anteriores oferecidos pelo PET e por meio de estudos e pesquisas de materiais recentes relacionados à ferramenta no site oficial do Geogebra. A divulgação foi feita para professores da cidade de Santa Maria - RS e, posteriormente, ofertou-se vagas para professores das demais regiões do Brasil.

\subsection{Exploração de novas funcionalidades do Geogebra}

O software contém várias opções de janelas e funcionalidades disponíveis. Antes da preparação do material para os alunos, foi realizada uma busca referente às novas versões do Geogebra e suas diferenças em comparação com as demais. o Geogebra é multiplataforma, portanto é uma excelente alternativa para estudos, dando liberdade para que tanto alunos quanto professores a utilizem onde preferirem.

Para o curso utilizou-se o Geogebra $6^{3}$ para desktop. A escolha da versão foi devido ser a mesma que está disponibilizada no site oficial da ferramenta, permitindo sua utilização sem a necessidade de instalação. Essa opção faz com que os usuários sintam-se livres para baixar a ferramenta ou utilizá-la pelo navegador de suas máquinas.

Além da avaliação de qual versão utilizar, descobriu-se uma funcionalidade capaz de criar um vínculo entre as atividades do Geogebra com o Google Classroom. Em maio de 2020, a Secretaria Estadual da Educação declarou o retorno às aulas de forma remota na modalidade de ensino à distância (EAD), recomendando o uso do Google Classroom propondo espelhar a escola no ambiente digital [G1 2020].

Como o Google Classroom passou a ser utilizado pela maioria dos professores da rede pública, a integração entre as duas plataformas mostrou-se muito interessante para ser adicionada à ementa do curso. As demais funcionalidades do Geogebra não tiveram grandes modificações, não sendo necessário um aprofundamento dos estudos.

\subsection{Ementa e aulas assíncronas}

A elaboração da ementa iniciou-se após a pesquisa de atualizações do Geogebra. Houve algumas mudanças na interface do software e do site, mas as opções principais foram

\footnotetext{
${ }^{3}$ https://www.geogebra.org/?lang=pt
} 
mantidas. Uma novidade encontrada, ainda na fase de exploração, foi o Classroom do Geogebra.

A sala de aula criada no site do Geogebra oferece avaliação síncrona, pois o professor pode ver em tempo real os estudantes realizando as atividades propostas, como mostra a Figura 1. O lado negativo dessa opção é a indisponibilidade de retornos aos alunos sobre as atividades, essa funcionalidade está disponível apenas para grupos. Os materiais didáticos, como documentos de texto ou vídeos, devem ser compartilhados através da criação de uma tarefa ou dentro de um grupo.

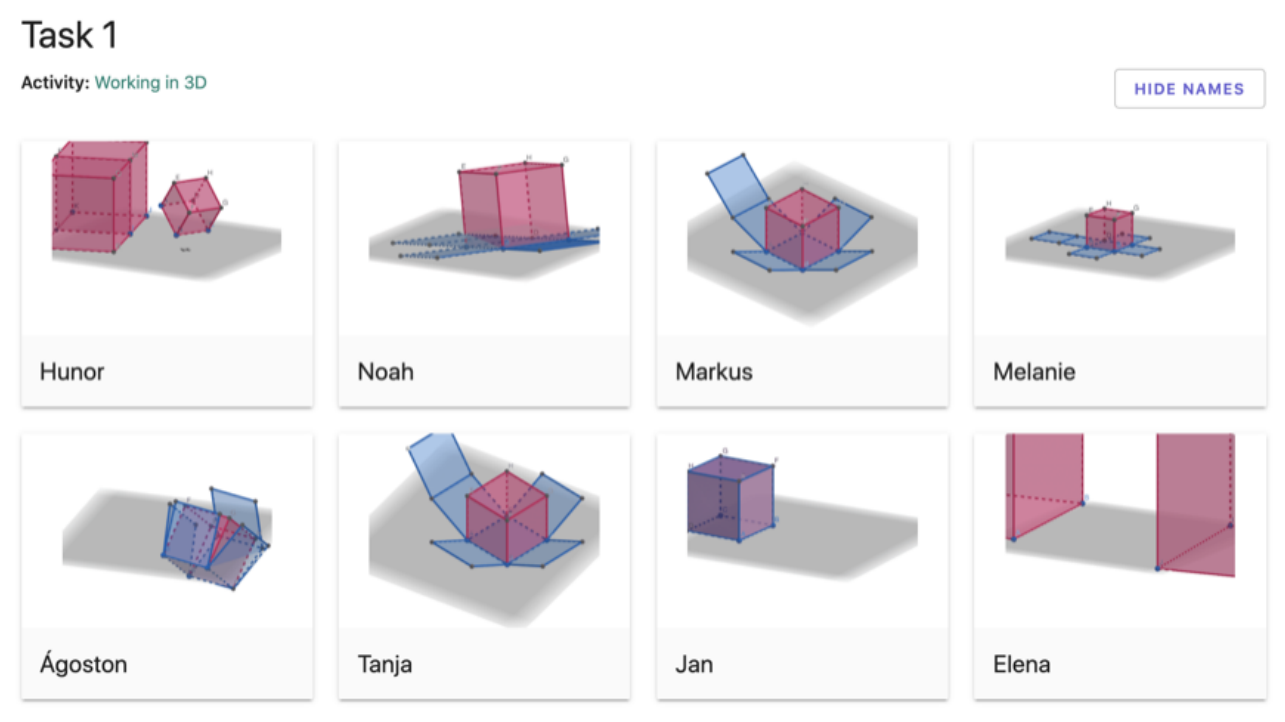

Figura 1. Visualização de uma tarefa sendo realizada em tempo real por diferentes alunos.

Os grupos funcionam de forma muito parecida ao Google Classroom, porém com uma interface diferente. Em resumo, para fazer o monitoramento de uma atividade de forma síncrona seria utilizado o Classroom e para avaliar e dar feedback para o discente seria utilizado um grupo. Em ambos os alunos precisam criar uma conta no Geogebra, além dos dois possuírem uma chave de entrada diferente.

Entretanto, o Classroom do Geogebra não foi incluído na ementa, pois os professores já se encontram com dificuldade para ajustar suas aulas e materiais no Google Classroom. Pensou-se que essa opção poderia confundi-los ainda mais, além de todas as questões citadas acima que acabam tornando a utilização não muito simples e prática.

A ementa final com todos os conteúdos abordados no curso ficou da seguinte maneira:

- Criação de tarefas no Geogebra: como disponibilizar materiais diversos como vídeos, arquivos PDF, imagens, adicionar applets prontos do Geogebra e questões.

- Vinculação de tarefas do Geogebra com o Google Classroom: como compartilhar as atividades criadas com as turmas existentes no Google Classroom.

- Interface do Geogebra: apresentação da interface inicial e nomenclaturas padrões utilizadas na ferramenta.

- Salvar e importar arquivos: opções para salvar os applets criados, como abrir arquivos .ggb e como importar e alterar applets de outros usuários. 
- Gráficos de funções: como criar gráficos utilizando as janelas algébrica e de visualização.

- Opções interativas: como utilizar controle deslizante, campo de entrada, texto com variáveis e exibir ou ocultar objetos.

- Trigonometria: opções disponíveis para criação de funções trigonométricas e ângulos.

- Geometria plana: como criar figuras geométricas.

- Geometria espacial: introdução à janela 3D, criação de sólidos geométricos e introdução à comandos.

Para as aulas, foram feitos vídeos explicativos, cada um com os conteúdos citados acima, disponibilizando-os no Youtube. Também realizou-se um vídeo apresentando o curso para os professores inscritos, e alguns vídeos extras fazendo exemplos úteis utilizando os conhecimentos adquiridos na aula em questão.

Essa metodologia de aulas assíncronas foi escolhida levando em consideração o público alvo, que por se tratar de adultos, a tendência é ter diversas ocupações. Além disso, dessa maneira os alunos têm a possibilidade de estudar e assistir às aulas quando e quantas vezes julgrem necessário. Pessoas que possuem problemas de conexão e que enfrentariam travamentos e perda de dados em aulas por webconferência também não são prejudicadas.

\subsection{Avaliação e didática adotada}

O acompanhamento dos alunos se deu através da criação de uma turma no Google Classroom exclusivamente para o curso. Os materiais foram separados em pequenos módulos, no qual eram disponibilizados diariamente, com pausa de um dia entre cada módulo.

Para contabilizar presença e validar o aprendizado, a cada aula, era publicada em conjunto uma atividade avaliativa referente à aula ou ao conhecimento adquirido até aquele momento. Colocações, dúvidas ou observações podiam ser feitos através de comentários na atividade, no mural do Google Classroom ou por meio das atividades, de maneira particular.

O curso, assim como os demais ministrados pelo PET-CC, contou também com certificação autenticada pela instituição. No curso de Geogebra em questão, para obtenção do certificado, estipulou-se que a média final deveria ser maior ou igual à 70 , sendo a variação das notas das atividades avaliativas de 0 à 100 .

\section{Primeira turma}

Para a primeira turma foram abertas 60 vagas, entretanto foram aceitos os 76 primeiros inscritos no Google Classroom, devido a alta demanda inicial. O tutor do PET-CC fez a divulgação incialmente às escolas da rede pública de Santa Maria, devido à projetos em parceria entre o PET-CC e a Secretaria de Educação do município. Posteriormente, divulgou-se também para professores de Matemática que participaram de turmas de edições anteriores do curso de Google Classroom, outra iniciativa do PET-CC.

Foram reservadas três semanas para curso, seguindo o planejamento da ementa e metodologia de publicações de aulas e atividades. O mesmo teve início no dia 21 de setembro e se extendeu até 12 de outubro de 2020. 
Além da disponibilização dos materiais planejados, ao longo do curso publicou-se alguns eventos relacionados ao Geogebra, como o I Encontro Internacional do GeoGebra 4 O objetivo do evento é de usuários do Geogebra em geral - alunos, professores e pesquisadores - compartilharem suas experiências com a ferramenta. $\mathrm{O}$ evento também conta com palestras e oficinas com temáticas abordadas no curso, como a utilização do Google Classroom com o Geogebra.

Quanto aos assuntos que não foram abordados no curso por não fazerem parte da ementa programada, providenciou-se duas apostilas, uma realizada pelo PET Matemática da mesma instituição e outra que encontra-se no próprio Geogebra para servir como material complementar. Ao fim do curso também indicou-se o site $O$ Geogebra 5 , famoso por seus materiais sucintos e de qualidade.

\subsection{Adesão e resultados}

Cerca de $46 \%$ dos alunos participaram ativamente do curso, como pode ser observado na Figura 2, realizando as atividades e retirando dúvidas quando necessário. Alguns participaram apenas das primeiras aulas, realizando duas ou três atividades. Os dois primeiros materiais foram pensados com o intuito de demostrar a vinculação do Geogebra com o Google Classroom. Esse processo não exige nenhuma experiência com o software, por conta disso, acredita-se que apenas a primeira parte seria o suficiente para aqueles que buscaram a ferramenta apenas para auxílio às aulas remotas.

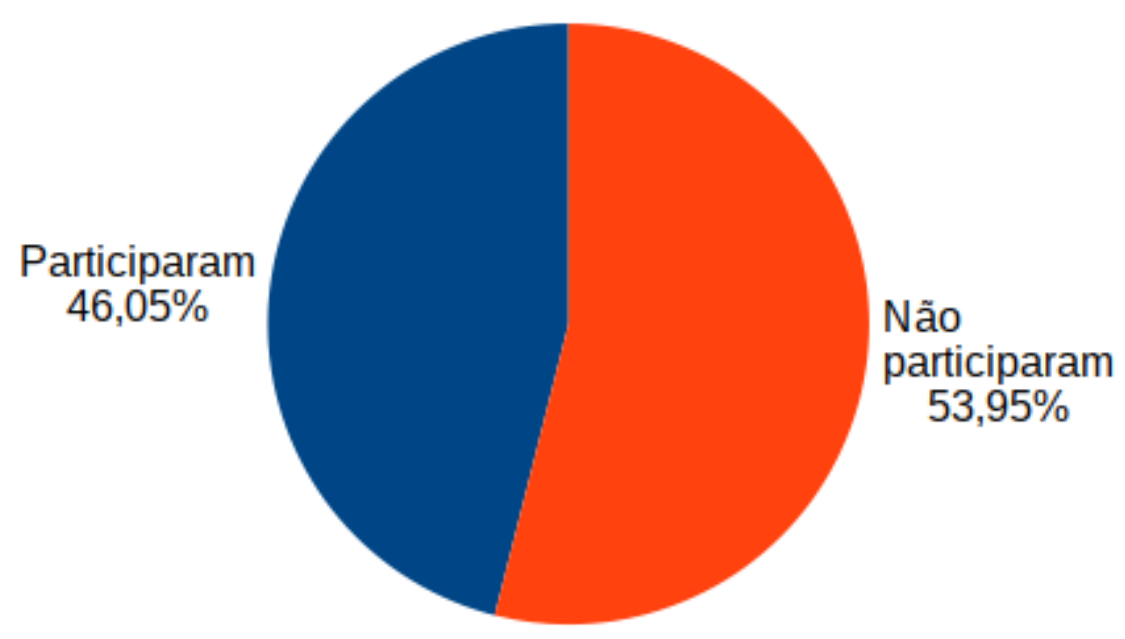

Figura 2. Índice de participação no curso.

Percebendo que o curso não estava tendo a adesão esperada pelos organizadores, houve um contato com os alunos para entender o porquê de não estarem participando

\footnotetext{
${ }^{4} \mathrm{http}: / /$ dalicenca.uff.br/encontro-internacional-do-geogebra/

${ }^{5}$ https://ogeogebra.com.br/site/
} 
ativamente. Os motivos foram bem variados, mas os principais foram: o excesso de cursos online em paralelo com as atividades acadêmicas, imprevistos que aconteceram durante o período do curso (impossibilitando o seu acompanhamento) e tempo para realizar as atividades previstas.

Dos $46 \%$ que estavam ativos em algum momento, 27 alunos obtiveram êxito em concluir o curso. Isso corresponde à $35.5 \%$ do total de professores inscritos como mostra a Figura 3 . O índice de aprovação foi abaixo do esperado, mas considerando apenas os que demonstraram alguma atividade no decorrer do curso, a aprovação é de quase $80 \%$. Além disso, para a outra metade que não conseguiu participar, os materiais estarão disponíveis no Google Classroom para acesso a qualquer momento.

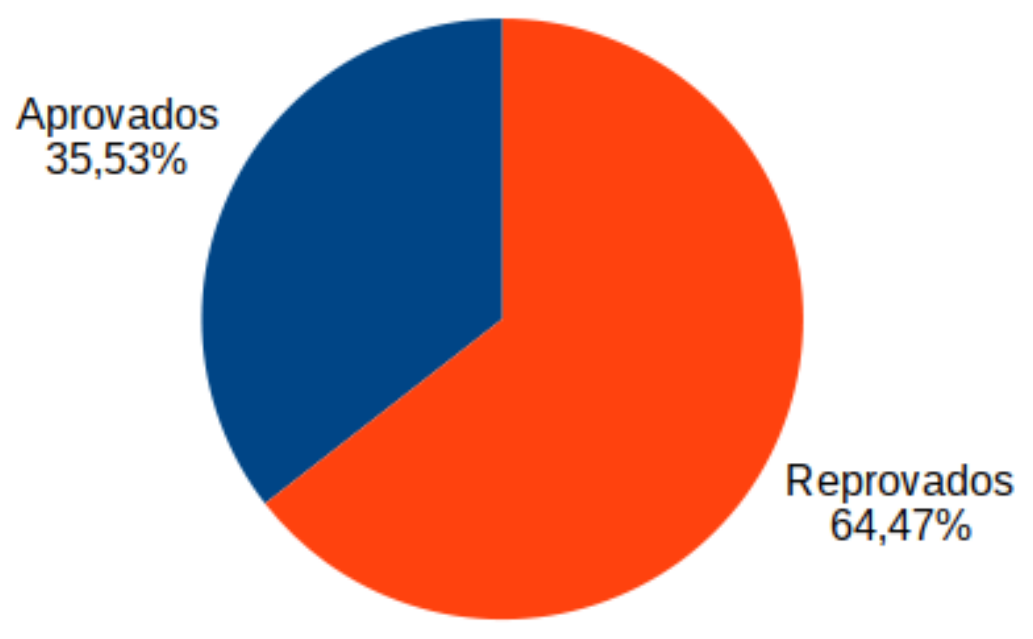

Figura 3. Índice de aprovação no curso.

Aplicou-se um questionário de satisfação para todos que quisessem contribuir com o aperfeiçoamento do curso. Do total, 21 inscritos responderam, sendo o curso muito bem aceito por eles, atendendo às expectativas dos participantes, como observa-se na Figura 4. sendo 1 equivalente a muito insatisfeito e 5 a muito satisfeito. O mais importante a ser ressaltado é que o aprendizado adquirido será útil no trabalho desses professores, segundo eles próprios, como mostra a Figura 5. Esse era o principal objetivo da realização do curso de Geogebra.

O formato de videoaulas assíncronas também foi aprovado pela maioria dos participantes de acordo com a Figura 6, por dar liberdade de escolha de horários para os estudos. Além disso, grande parte dos professores se interessaram pelo curso com o intuito de realmente aprender sobre o Geogebra, destacando o trabalho árduo e preocupação que esses educadores estão tendo durante a pandemia para melhorar o ensino de seus estudantes.

Um ponto destacado por vários dos professores foi o engajamento dos tutores, para 


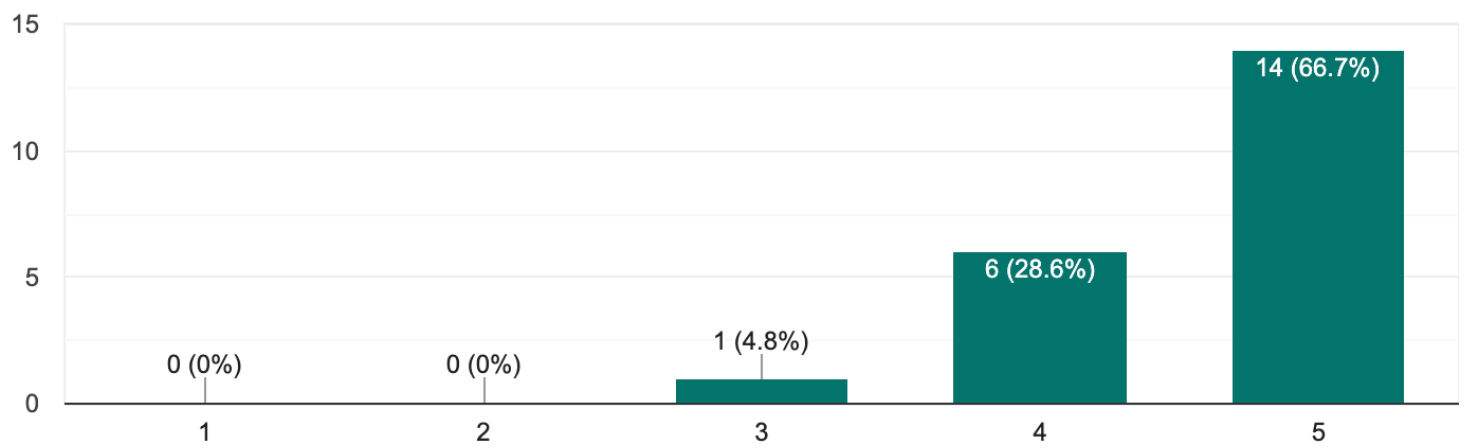

Figura 4. Aprovação do curso de acordo com as expectativas iniciais.

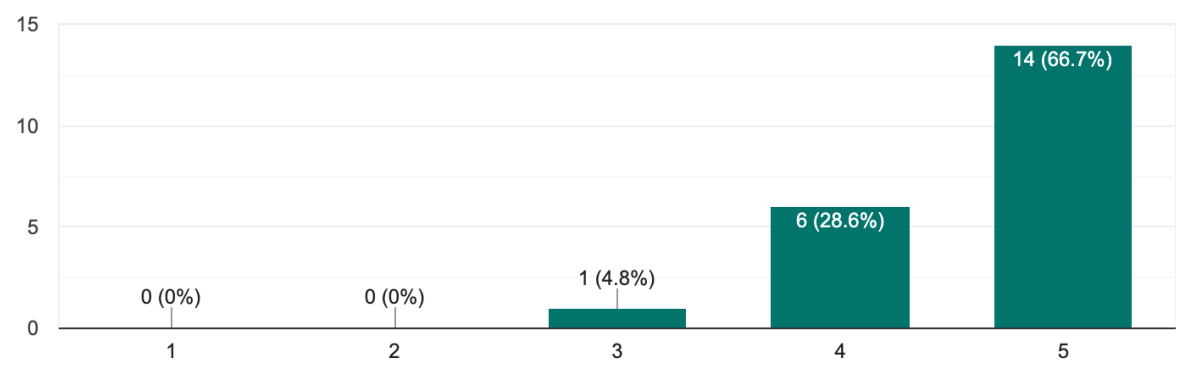

Figura 5. Utilidade e importância do que foi aprendido no curso no trabalho.

retirar dúvidas, fazer colocações e divulgar eventos. O formato do curso, por proporcionar um atendimento direto e rápido, foi muito bem avaliado nesse quesito. Em contrapartida, alguns afirmaram que o curso poderia ser mais extenso, permitindo explorar as demais funcionalidades do Geogebra. Além disso, também foram feitas observações quanto aos enunciados das atividades, que devem ser reformulados para ter mais clareza.

Muitos afirmaram terem interesse em participar de cursos futuros voltados para educação como observa-se na Figura 7, no mesmo formato, sejam eles do Geogebra ou não. Também foram feitas sugestões para que em edições futuras, o curso de Geogebra tenha turmas separadas por nível de ensino - anos iniciais e finais do fundamental e séries do ensino médio. Também foi sugerida a realização de lives com pessoas da área que possuem experiência no uso do Geogebra para o ensino.

\section{Conclusão}

O desenvolvimento do curso de Geogebra para professores de escolas públicas teve como meta principal ampliar os horizontes e a visão educacional para aulas à distância no cenário pandêmico. Considerando que tanto estudantes como professores estão passando por dificuldades, o Geogebra aliado ao Google Classroom pode ser uma alternativa simples para os docentes além de estimulante e divertido para os alunos.

Para cumprimento do objetivo, realizou-se uma lista de videoaulas para explanar as funcionalidades e opções disponíveis pelo Geogebra. Além disso, foi criada uma turma no Google Classroom com professores de diferentes locais para acompanhamento da evolução do aprendizado deles e disponibilização dos materiais criados.

O diferencial do curso em relação aos diversos tutoriais encontrados na internet re- 


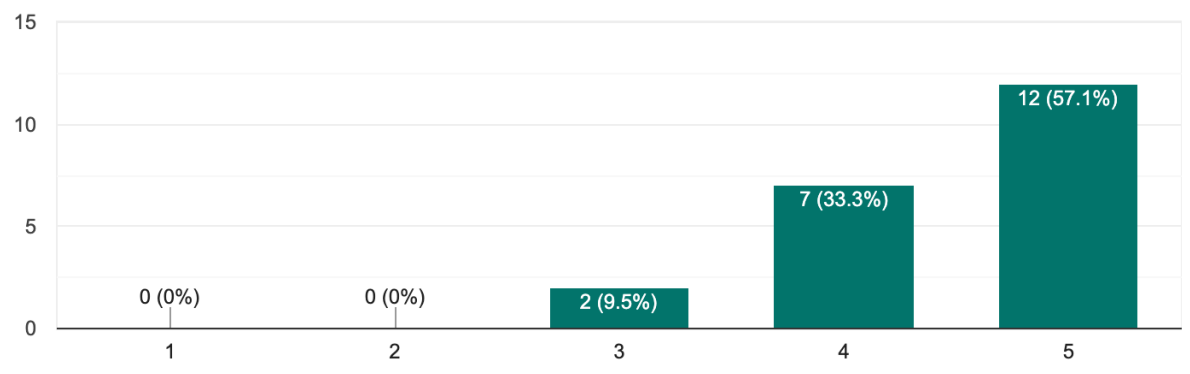

Figura 6. Avaliação de aulas assíncronas para o curso.

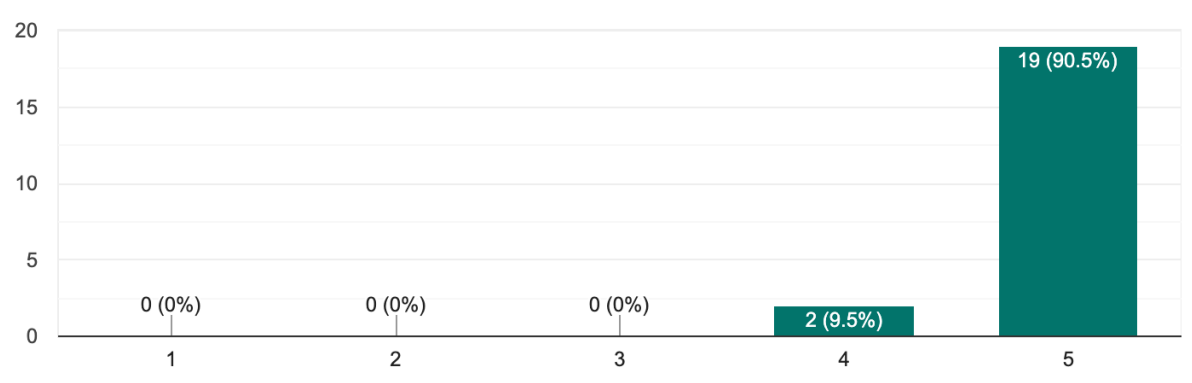

Figura 7. Interesse dos professores em participar de cursos futuros.

lacionado ao Geogebra é o monitoramento e acompanhamento dos alunos. Com a criação da turma no Google Classroom foi possível retirar dúvidas gerais ou específicas, dando atendimento especial a cada um de forma fácil e rápida. A participação nas atividades por parte dos inscritos não foi a esperada, porém, os que participaram ativamente, conseguiram finalizar o curso e tiveram suas dúvidas sanadas.

As maiores dificuldades da turma não estavam relacionadas ao Geogebra em si, mas sim em detalhes, como a configuração padrão do navegador que impedia alguma funcionalidade específica. Na entrega das atividades notou-se a inaptidão de alguns com tecnologias em geral, ressaltando a necessidade de auxílio à comunidade, principalmente no momento atual.

Também houve alguns alunos que afirmaram ter problemas com horários, pois as aulas remotas estão exigindo uma carga horária maior que a do trabalho presencial. Além das videoaulas e demais materiais ficarem disponíveis na turma, pretende-se realizar outras edições do curso, com o intuito de atingir e impactar um maior número de pessoas de maneira eficaz.

Uma modificação que julgou-se necessária para os cursos futuros, tanto para o de Geogebra quanto outros que venham a surgir, é a criação de materiais para leitura. As pessoas possuem formas de aprendizado distintas, portanto acredita-se que a inserção de documentos de texto em formato PDF podem auxiliar na absorção de conhecimento de alguns. As sugestões de turmas separadas por nível de ensino (fundamental e médio) e criação de lives com profissionais que utilizam o Geogebra para o ensino serão avaliadas para aplicação.

Outro ponto que pode ser discutido na elaboração da próxima edição do curso é a sua estruturação. Possivelmente a ementa pode ser revista, de forma a incorporar novos conceitos, assim como o período do curso pode ser ampliado, passando de 3 para 4 ou 
mais semanas, dando tempo extra para a realização das atividades propostas.

\section{Referências}

Bortolossi, H. J. (2016). O uso do software gratuito Geogebra no ensino e na aprendizagem de estatística e probabilidade. VIDYA, 32(2):429-440.

Brandt, S. T. J. and Montorfano, C. (2008). O software geogebra como alternativa no ensino da geometria em um minicurso para professores. http://www.diaadiaeducacao.pr.gov.br/portals/pde/arquivos/ 329-4.pdf. Último acesso em 22 de Outubro de 2020.

Fantinel, G. A. and et al. (2020). Curso de google classroom para professores. https: //portal.ufsm.br/jai/trabalho/anais.html. Último acesso em $22 \mathrm{de}$ Outubro de 2020.

Freire, R., Cunha, A. R., and Maximiano, R. P. (2013). Matemática, lúdico e geogebra: integração a favor de ensinamentos e aprendizagens diversas. In VI Congresso Internacional de Ensino de Matemática, Canoas, Brasil.

G1 (2020). Aulas das redes pública e privada retornam a partir de $1^{\circ}$ de junho com ensino à distância no rs. https://gl.globo.com/rs/rio-grande-do-sul/ noticia/2020/05/27/aulas-das-redes-publica-e-privadaretornam-a-partir-de-1o-de-junho-com-ensino-a-distanciano-rs.ghtml. Último acesso em 22 de Outubro de 2020.

Halberstadt, F. F. (2016). Possibilidades de uso do geogebra no ensino e aprendizagem da geometria: algumas reflexões. Educ.Tecnol., 21(3):32-44.

Masola, W. J. and Allevato, N. S. G. (2019). Dificuldades de aprendizagem matemática: algumas reflexões. Educação Matemática Debate, 3(7):52-67.

Mathias, C. V., Silva, H. A. D., and Leivas, J. C. P. (2019). Provas sem palavras, visualização, animação e GeoGebra. Revista do Instituto Geogebra Internacional de São Paulo, 8(2):62-77.

Preiner, J. (2008). Introducing dynamic mathematics software to mathematics teachers: the case of geogebra. In Dissertation in Mathematics Education, Salzburg, Áustria. 